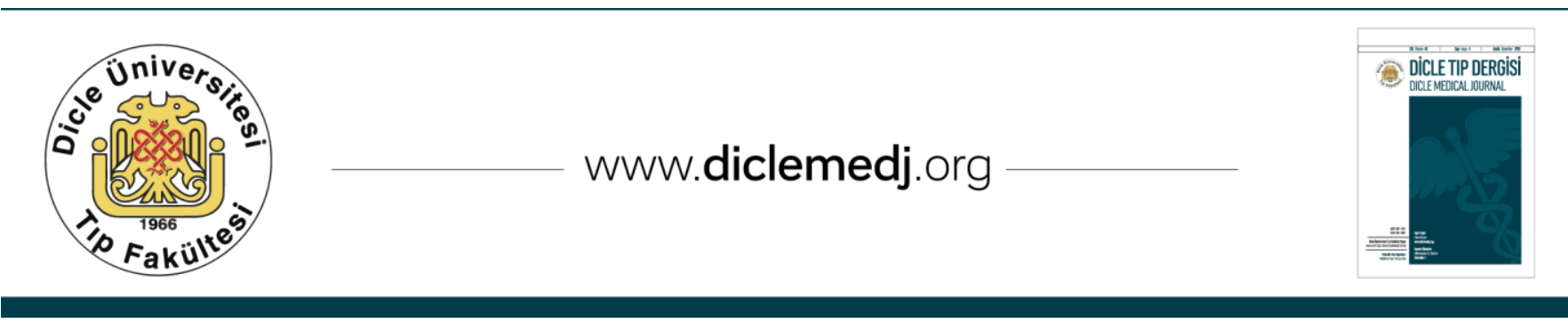

Özgün Araștırma / Original Article

\title{
İdiopatik granulomatöz mastit: Zor tanı ve yönetim
}

\author{
Fatih Çiftci ${ }^{1}$, Turgut Anuk ${ }^{2}$ \\ 1 İstanbul Gelișim Üniversitesi Sağlık Hizmetleri MYO, İstanbul, Türkiye \\ 2 Kafkas Üniversitesi Tıp Fakültesi Genel Cerrahi Bölümü, Kars, Türkiye
}

Geliş: 25.10.2016 Revizyon: 10.04.2017 Kabul Tarihi: 17.04.2017

\section{Özet}

Amaç: İdiopatik granulomatöz mastit (IGM) nadir bir enflamatuar hastalıktır. Etyolojisi müphem olduğundan tanısı ve tedavisi zordur. İGM yönetimi kapsamlı bir değerlendirmeyi gerektirir; tedavi yöntemini standardize etmek ve optimal olanı belirlemek de zordur. Bu çalışmada İGM nedeniyle tedavi edilen hastalarda klinik ve radyolojik bulgular, tedavi yaklaşımı, klinik seyir ve nüks oranının irdelenmesi amaçlanmıştır.

Yöntemler: Çalışmamızda Temmuz 2003 ile Aralık 2015 arasında histopatolojik İGM tanısı konulan hastalarda tıbbi raporlar, ultrasonografi (USG) ve mamografi (MMG) bulguları, klinik seyir ve nüks oranları tıbbi kayıtlardan retrospektif elde edildi.

Bulgular: Tüm hastalarda ağrılı, sert ve düzensiz kitle ortak bulgu idi. Parenkim heterojenitesi, apse ve kitle görünümü USG bulguları iken; asimetrik yoğunluk MMG'nin ana bulgusu idi. Yirmiüç $(\% 63,8)$ hastada geniş lokal eksizyon yapılırken 13 (\%36) hastada insizyonel biyopsi ve apse drenajı yapılmış idi.

Sonuç: Granulomatöz mastitte fizik muayene bulguları meme karsinomu ile örtüşmektedir. USG parankim heterojenitesi ve apse oluşumu ile birlikte özellikle büyümüş aksiller lenf nodülünün bulunması enflamatuar sürecin varlığını destekler. Ancak bu bulgular karsinomu ekarte etmez. Bu nedenle maligniteyi gözden kaçırmamak için histopatolojik tanı çalışması kaçınılmazdır. İGM tedavisinde genişletilmiş eksizyon rol oynayabilir.

Anahtar kelimeler: Meme, Mastitis, Granulomatöz, Tedavi, muayene

DOI: $10.5798 /$ dicletip.319745

Yazışma Adresi / Correspondence: Fatih Çiftci, Bulvar İstanbul sitesi E4/79 İshakpaşa sk. Başakșehir İstanbul e-mail:oprdrfatihciftci@gmail.com 


\title{
İdiopathic granulomatous mastitis: A Hard Disease to Diagnose and Manage
}

\begin{abstract}
Objective: Idiopathic granulomatous mastitis (IGM) is an infrequent chronic inflammatory condition of breast. It is hard to diagnose and treat due to its unusual aetiology and pathogenesis. The goal of this study is to assess the clinical and radiological findings, type of treatment approaches, clinical outcome, and recurence in patients treated with IGM.

Methods: We included the patients diagnosed with IGM histopathologically between July 2003 and October 2015. Ultrasonography (US) and mammography (MMG) results, follow-up and recurrence data, and medical outcome data were gained from patients' records.

Results: The symptom that is common in all patients was an irregular, firm, and painful mass. Main USG findings were abscess and mass formation, and parenchymal heterogeneity, while main MMG finding was an increase in asymmetric density. As surgical technique, wide local excision was performed in 23 (63.8\%) patients, and incisional biopsy with abscess drainage in $13(36 \%)$ patients.

Conclusions: IGM often poses a diagnostic dilemma by mimicking malignancy. While USG finding of parenchymal heterogeneity, abscess formation with axillary lymphadenomegaly support the diagnosis of inflammation, these findings do not necessarily exclude carcinoma. Hence, histopathologic verification is obligatory to provide a certain diagnosis. Extensive surgery may play a role in treatment of IGM.
\end{abstract}

Keywords: Breast, Mastitis, Granulomatous, Treatment, Examination

\section{GíRiş}

İdiopatik granülomatöz mastit (İGM), memenin nadir enflamatuar hastalığıdır ${ }^{1}$. İki nedenle önemlidir; birincisi, İGM klinik ve radyolojik bulgular bakımından meme karsinomuna benzeyebilir, kesin tanı ancak histopatoloji ile konulur. İkinci nokta ise fistül ve apse varlığında İGM tedavisi zorlaşmaktadır. Etiolojisinin belirsiz olması ve hastalığın nadir oluşundan dolayı tanı ve tedavisinde güçlükler yaşanabilmektedir ${ }^{2}$. Yerleşmiş bir optimal tedavi yaklaşımı henüz bulunmamaktadır. Ancak medikal tedavi, geniş lokal eksizyon ve apse drenajı tercih edilen yaklaşımlar arasındadır ${ }^{3}$. $\mathrm{Bu}$ çalışmanın amacı İGM nedeniyle tedavi edilen hastalarda klinik ve radyolojik bulgular, tedavi yaklaşımı, klinik seyir ve nüks oranlarını irdelemektir.

\section{YÖNTEMLER}

Çalışmamızda Temmuz 2003 ile Aralık 2015 arasında histopatolojik olarak İGM tanısı konulan 36 hastanın kayıtları retrospektif olarak gözden geçirildi. Hastaların şikayetleri, gebelik varlığı, daha önceki gebelik sayısı, kontraseptif kullanımı, takip bilgileri ve nüksle ilgili bilgiler klinik kayıtlardan elde edildi. Tüm hastalara meme muayenesi ve USG, 40 yaş üstü olanlara hem rutin tarama kapsamında hem de maligniteyi ekarte etmek amaciyla mamografi (MMG) yapılmış idi. Bir hastaya Magnetik Rezonans görüntüleme (MRG) yapılmış idi. Tüm hastalar kliniğimizde düzenli olarak takip edilmiş idi. İstatistik analizler SPSS 16.0 kullanılarak uygulandı.

İnsizyonel veya geniş lokal eksizyon biyopsi yapılan hastalarda histopatolojik çalışma kaydedildi. Geniş lokal eksizyon tanımı minimum lezyonsuz 5-10 mm radiyal kenar esasına göre yapıldı.

Drenajı takiben apse kavitesine insizyonel biyopsi yapılarak en az 4 doku örneği alındı. Deriye fistül oluşumu söz konusu olduğunda etkilenen deri de eksize edildi.

Epiteloid histiositler, Langhans dev hücreleri ile birlikte lenfositler, plasma hücreleri ve nadiren de lobüllerin merkezinde eozinofil hücreleri içeren granulomlu enflamatuar reaksiyonlara histopatolojik olarak İGM tanısı konuldu. Tüm aspiratlar ve doku örnekleri, hem hematoksilen - eosin boyası hem de tüberküloz ve mantar 
enfeksiyonuna yönelik özel boyama ile incelendi. Apse oluşumu olan hastalarda aerobik bakteriler (Streptococcus, Staphylococcus, Enterococcus, Klebsiella, Pseudomonas, E.coli) ve anaeroplar (Clostridium, Bacteroides) için kültür ekildi. Lezyonlar düzelene kadar her ay fizik muayene ve USG yapıldı.

\section{BULGULAR}

Histopatolojik olarak İGM tanısı konulan 36 hastanın tüm takip bilgileri incelenerek çalışmaya dahil edildi. Ortalama yaş $39 \pm 1$ olup yaş aralığı 27 ile 60 arası idi. Hastaların \%88,8 $(n=32)$ doğurgan yaşta idi ve çocuk sahibi idi. Son bir yll içinde hiçbir hastada oral kontraseptif kullanımı veya laktasyon hikayesi yoktu. Bütün hastalardaki ortak bulgu ağrılı, sert ve belirsiz kitle oluşuydu. $24 \quad(\% 66,6)$ hastada ağrılı kitlesel lezyonlara eritem ve ödem gibi cilt değişiklikleri eşlik ediyordu. 21 $(\% 58,3)$ hastada sol, $10(\% 27,5)$ hastada sağ ve $5(\% 13,8)$ hastada her iki meme etkilenmiști. Lezyonlar $7(\% 19,4)$ hastada üst dış kadranda, $2(\% 5,5)$ hastada üst iç kadranda, $2(\% 5,5)$ hastada alt iç kadranda, $5(\% 13,8)$ hastada alt dış kadranda, $10(\% 27,7)$ hastada periareolar bölgede ve $10(\% 27,7)$ hastada diffüz yerleșimli idi (Tablo 1).

Tablo 1: Meme lezyon yerleşim yerleri

\begin{tabular}{ll}
\hline Lezyon lokasyonları & Sayı(\%) \\
\hline Diffüz & $10(27,7)$ \\
Periareolar bölge & $10(27,7)$ \\
Alt dış & $5(19,4)$ \\
Üst diş & $7(19,4)$ \\
Alt iç & $2(5,5)$ \\
Üst iç & $2(5,5)$ \\
\hline
\end{tabular}

USG de $10(\% 27,7)$ hastada belirgin kitlesel oluşumu olmadan parenkimal heterojenite, 10 $(\% 27,7)$ hastada düzensiz kitle, 6 (\%16,6) hastada apse oluşumu, $2 \quad(\% 5,5)$ hastada düzensiz kitle ve heterojenite, $6 \quad(\% 16,6)$ hastada heterojenite ve apse oluşumu, $2(\% 5,5)$ hastada heterojenite, apse ve kitle saptandı, 21
$(\% 41,5)$ hastada eşlik eden büyümüş aksiller lenf nodları vardı (Tablo 2).

Tablo 2: IGM'li hastaların USG bulguları

\begin{tabular}{ll}
\hline USG bulguları & Sayı(\%) \\
\hline İrregüler kitle & $10(27,7)$ \\
Parankimal heterojenite & $10(27,7)$ \\
Abse Formasyonu & $6(16,6)$ \\
Abse formasyonu+heterojenite & $6(16,6)$ \\
Heterojenite+İrregüler kitle & $2(5,5)$ \\
Abse formasyonu+heterojenite+kitle & $2(5,5)$ \\
\hline
\end{tabular}

On hastada MMG yapıldı. MMG, 4 hastada asimetrik dansite, 3 hastada asimetrik dansite ile birlikte cilt kalınlaşması ve diğer 3 hastada asimetrik dansite, cilt kalınlaşması ve meme ucu retraksiyonu tespit edildi. Hastalık tutulumu yaygın, bilateral ve tedaviye dirençli olan bir hastada MRG yapıldı (Resim 1). Bu hastada ek bilgi elde etmek için MRG gerekli bulundu.

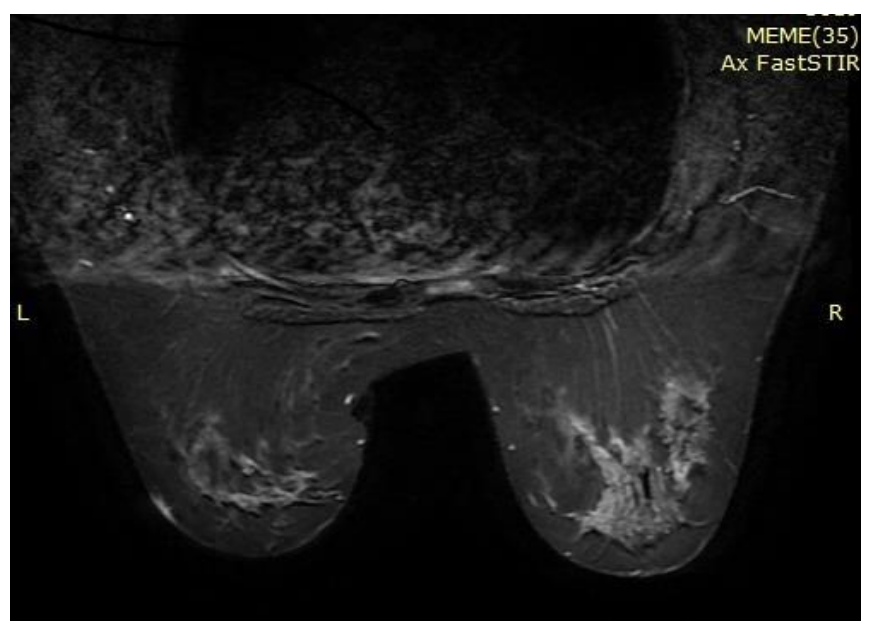

Resim 1: Sağ meme üst ve orta hatta her iki iç ve dıș kadranları tamamen dolduran postkontrast subtraksiyon görüntülerde yaklaşı 9x6 cm'lik bir alanı etkileyen bölgesel - yamavari küme tarzında kontrast fiksasyonu gösteren, dinamik görüntülerde tip 2 kontrastlanma kinetiği saptanan heterojen sinyal alanı mevcuttur. Sol meme alt dış kadranda subkutan doku içerisinde 18x11 $\mathrm{mm}$ boyutlarında postkontrast subtraksiyon görüntülerde persistan kontrast fiksasyonu gösteren inflamatuar kistik nodül mevcuttur. 
$23(\% 63,8)$ hastada geniş lokal eksizyon ve 13 (\%36,1) hastada insizyonel biyopsi ve abse drenajı yapıldı. Her olguda epiteloid histiosit, lenfosit, plasma hücresi, polimorfonükleer lökosit ve multinükleer langhans tipi dev hücreler vardı (Resim 2,3). Kazeifikasyon nekrozu yoktu. Tüm hastalarda non-spesifik bakteri kültürü yapıldı; anlamlı bir üreme saptanmadı. Apse oluşumu olan tüm hastalara amoksisilin $875 \mathrm{mg}$ ve klavulonik asit $125 \mathrm{mg}$ kombinasyonu verildi.

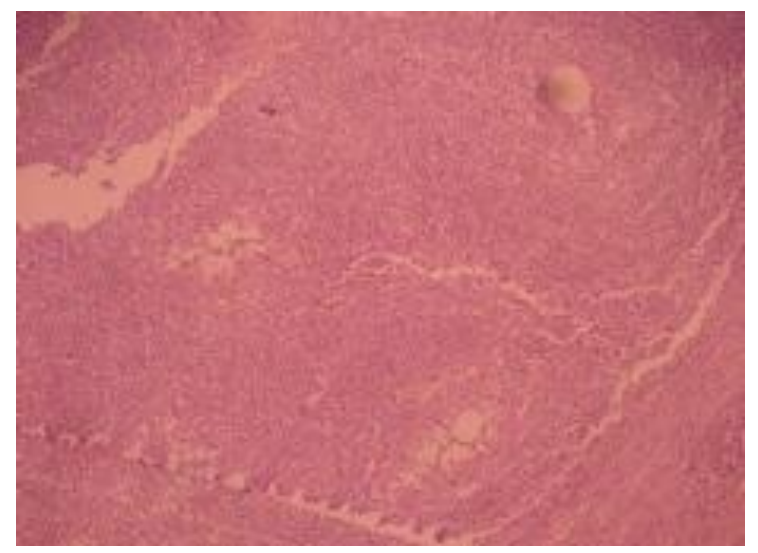

Resim 2: Küçük büyütmede, üç ayrı nonkazeifiye küçük granulom yapısı fark edilmektedir.

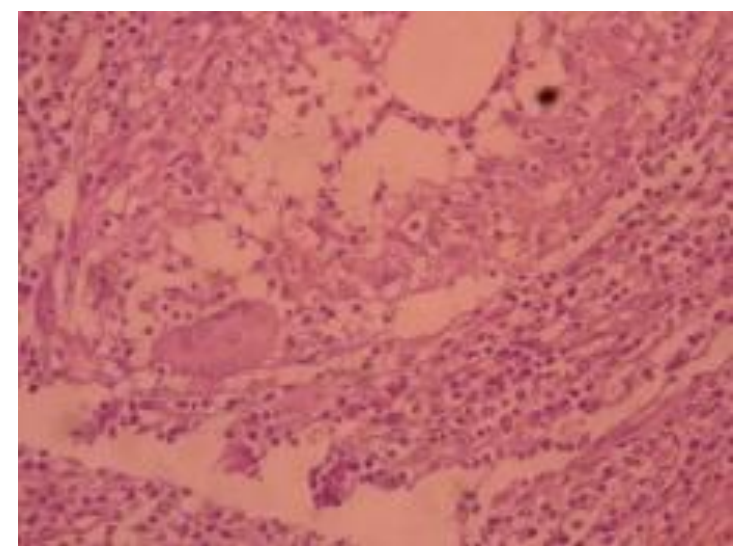

Resim 3: Büyük büyütmede granulomların epiteloid histiositlerden ve multinükleer dev hücrelerden oluştuğu görülmektedir.

Ortalama takip süresi 35.9 (aralık 6-60) aydı. Geniş lokal eksizyon tedavisi 23 hastada başarılı oldu. Bir hastada 24 ay sonra memenin bir başka kadranında nüks gelişti ve reeksizyonla tedavi edildi. Abse oluşumu olan hastalarda ortalama iyileşme süresi $6.14-11$ aydı. Yaygın ve çift taraflı lezyonu olan bir hastada defalarca apse oluşumu ile nüks yaşandı. Bu hasta başlangıçta kortikosteroid kullanmaktan çekindi. Ancak yaşam kalitesinin etkilenmesi nedeniyle kullanmaya mecbur kaldı. Kortikosteroid olarak prednizon $16 \mathrm{mg}$ dozu günde 2 kez uygulandı (Tablo 3 ).

Tablo 3: Hastalara yapılan tedavi çeşidi ile nüks arasındaki dağılım

\begin{tabular}{llll}
\hline Cerrahi tipi & Hasta sayısı & $\begin{array}{l}\text { Steroid } \\
\text { tedavisi } \\
\text { verilen }\end{array}$ & $\begin{array}{l}\text { Nüks } \\
\text { görülen }\end{array}$ \\
\hline $\begin{array}{l}\text { Geniş lokal } \\
\text { eksizyon }\end{array}$ & $23(\% 63,8)$ & - & $1(\% 4,3)$ \\
\hline $\begin{array}{l}\text { Insizyonel } \\
\text { biyopsi+drenaj }\end{array}$ & $13(\% 36)$ & $1(\% 7,6)$ & - \\
\hline Total & $36(\% 100)$ & $1(\% 2,8)$ & $1(\% 2,8)$ \\
\hline
\end{tabular}

\section{TARTIŞMA}

İGM, çoğunlukla doğurgan yaştaki kadınları etkileyen memenin benign, enflamatuar bir hastalığıdır ${ }^{3}$. Çalışmamızda 3 hasta hariç bütün hastalar doğurgan yaşta ve çocuk sahibi idi. Lokal irritan madde, oral kontraseptif hapları, virüsler, mantar, parazit infeksiyonu, hiperprolaktinemi, diabetes mellitus, sigara içimi, alfa- antitripsin eksikliği ve otoimmünite bozukluğu gibi birçok neden etiyolojik faktör olarak düşünülmüş̧ olup ancak kanıtlanmamıştır ${ }^{3-8}$.

İGM çoğunlukla tek taraflı memede sinırları belirsiz ağrılı sert kitle olarak prezente olur ${ }^{1-8}$. $\mathrm{Bu}$ lezyon memenin herhangi bir kadranında yerleşik olabilir8. İGM'de granulomatöz enflamasyon cilt kalınlaşması, sinüs ve apse oluşumu, aksiller lenfadenopati ve meme retraksiyonuna yol açabilir. Bu nedenle meme karsinomu ile karışabilir1,3,8. Bütün hastalar polikliniğimize ağrılı kitle şikayeti ile başvurmuştu ve bunların \%66'sında cilt değişiklikleri de vardı. Lezyonlar \%41,7 oranında subareolar bölgede ve yaygın yerleşim eğilimli idi. İGM, her iki memede aynı sıklıkta görülür, \%25 bilateral bulunabilir. 
Klinik olarak en sık olarak memede ağrısız ya da ağrılı ele gelen kitle tarzında ortaya çıkar. Akut inflamasyonu akla getirecek şekilde kısa zamanda ortaya çıkan kızarıklık, sıcaklık artışı, hassasiyet şeklinde görülebildiği gibi daha kronik süreçli meme cildinde fistül, apse, ülserasyon, meme başı retraksiyonu, meme başı akıntısı gibi meme kanserini düşündüren bulgularla da seyredebilir6,8,9. Serimizdeki 3 hastada bilateral ve yaygın tutulum vardı. Tüm kitleler belirsiz sinırlı ve sertti. 14 (\%41,7) hastada büyümüş aksiller lenf nodu olup USG'de şüpheli malignite değil reaktif lenfaenopati olarak değerlendirildi.

Çoğu hastamızda USG ve MMG ile sinırları belirsiz ve düzensiz kitle saptandı. USG ve MMG bulguları, İGM veya meme karsinomu tanısı için spesifik değildir. Memiş ve arkadaşları düzensiz hipoekoik kitle ve bu kitleyle bağlantısı olan hipoekoik tübüler alan görünümünü en sik sonografik bulgu olarak bildirmiştir ${ }^{9}$. Başka çalışmalarda parenkimal heterojenite ve karışık eko paternli bölgeler bildirilmiștir.

Çalışmamızda en sık USG bulguları parenkimal heterojenite, düzensiz hipoekoik kitle ve apse oluşumu idi. Hastaların \%41,7 sinde büyümüş aksiller lenf nodları vardı. Bu lenf nodlarında USG'de kortikal kalınlaşma (cut-off $2.5 \mathrm{~mm}$ ) veya yağlı hilus yokluğu gibi malignite düşündüren bulgular yoktu. Kanaatimiz odur ki; fizik muayene bulguları ilerlemiş meme karsinomunu düșündürürken USG bulgularında parenkimel heterojenite ve apse oluşumu ile birlikte özellikle büyümüş reaktif aksiller lenf nodlarının varlığı, enflamatuar granulomatöz sürecin varlığını desteklemektedir. Ancak, bu bulgular nonspesifik olup karsinomu ekarte ettirmez. Bu nedenle ayırıcı tanıda histopatoloji vazgeçilmezdir10,11. USG, MMG'ye kıyasla daha spesifik bulgular verebilir. İGM, USG'de çoğunlukla sınırları düzensiz, hipoekoik heterojen kitle ayrıca kitleyle devamlılık gösteren hipoekoik tübüler uzantılar tarzında görüntü verir. Ultrasonografide diğer izlenen bulgular, tek veya çok sayıda, tübüler veya nodüler hipoekoik oluşumlar ya da parenkimal ekojenitede fokal azalma ile arkasında akustik gölgelenme gösteren alanlardır. İGM tanısında özellikle tübüler hipoekoik lezyonların anlamlı olduğu bildirilmiştir.

MMG de en sık bulgu parenkimal bozulma veya mikrokalsifikasyon içermeyen sınırları belirsiz kitle ve yaygin veya fokal asimetrik dansite artışıdır ${ }^{7,12}$. Önceki raporlara uyumlu olarak bizim de hastalarımızın tümünde asimetrik dansite saptandı.

Bazı çalışmalara göre İGM'yi karsinomdan ayırt etmek için MRG katkı sağlamaz ${ }^{6,7}$. Öte yandan MRG'de saptanan lezyona yönelik radyolojik bulguların genelde şüphe bırakmadığını ve karsinomun ayırıcı tanısında katkı sağlayabileceğini bildiren çalışma da mevcuttur ${ }^{12}$. MRG incelemesinde granülomatöz mastite özgü bir görünüm literatürde bildirilmemiştir. Tanımlanan MRG incelemelerinde çevresel kontrastlanma gösteren lezyondan, irregüler heterojen hiperintens lezyonlara kadar değişen görünüm özellikleri olabileceği belirtilmiştir. $\mathrm{Bu}$ görünüm özelliklerinin farklı evrelerdeki inflamatuar süreçten köken alabileceği akla gelmektedir. MRG, İGM'yi diğer enflamatuar ve granulomatöz hastalıklardan ayırt etmede rol oynamaz ${ }^{1,8,12}$.

USG ve MRG yeteri kadar spesifik değildir; İGM ile karsinom, bakteriyel mastit gibi enflamatuar lezyonlar, tüberküloz mastit, sarkoidoz ve Wegener granulomatozu gibi lezyonların ayırıcı tanısında yetersiz kalmaktadır ${ }^{8}$. Fizik muayene ve görüntüleme teknikleri kesin tanı koyduramadığı için histopatolojik tanı gerekir. $\mathrm{Bu}$ amaçla ince iğne aspirasyon sitolojisi (FNAC), core insizyonel ve eksizyonel biyopsi ile histopatolojik tanı çalışması yapılabilir?. FNAC'in faydası ve güvenirliği tartışmalıdır. Bazı yazarlar FNAC'in faydalı olduğunu savunurken diğerleri FNAC ile granulomatöz lezyonlar arasında ayrım yapılamayacağı görüşündedir6,13-15. Çalışmamızda tüm hastalarda histopatolojik tanı eksizyonel ve 
insizyonel biopsi ile konulmuştur. FNAC tercih edilmemiştir.

İGM için optimal tedavi yaklaşımı tartışmalıdır. Geniş lokal eksizyon ve kortikosteroid uygulaması ilk basamak tedavisi olarak önerilmektedir. Özellikle geçmiş yıllarda lezyonun eksizyonunun yeterli olduğu düşünülürken, takip edilen hastalarda eksizyon bölgesinde sıklıkla fistül ve nüks geliştiği görülmüştür. Günümüzde sı kullanılan kortikosteroid tedavisi ilk olarak 1980 yılında DeHertogh ${ }^{15}$ tarafından önerilmiş ve başarılı sonuçlar bildirilmiştir. Lal ve arkadaşları ${ }^{16}$, diğer etyolojik faktörler dışlandıktan sonra İGM tanısı alan ve klinik bulguları hafif olan hastaların, sadece klinik olarak takip edildiklerinde bile spontan regresyon olabileceği, oral prednisolon tedavisinin ciddi klinik bulguları olan hastalara saklanması gerektiğini bildirmişlerdir. Kim ve ark. ${ }^{17}$ diğer tedavilere dirençli olgularda, klinik cevap sınırlı olsa bile, metotreksat veya azotioprin gibi immünosupressif ajanların kullanılabileceğini; Asoğlu ve ark. ${ }^{18}$ ise medikal tedaviye cevapsızlık ve tekrarlayan abse veya fistül gibi klinik bulgular varlığında, geniş lokal eksizyon veya gerekirse mastektominin bile uygulanabileceğini bildirmişlerdir. Cerrahi eksizyon hala geçerli bir tedavi seçeneğidir. Geniş lokal eksizyon uygun seçim olabilir; zira kesin tanı ve tedavi imkanı sağlar. Geniş lokal eksizyonun mümkün olduğu durumda sonrasında ilave tedavi gerekmemektedir. Geniş lokal eksizyon sonrasında çeşitli oranlarda (\%5,5-50) nüks bildirilmiştiri, ${ }^{1,8}$.

Geniş lokal eksizyon yapılan 15 hastamızın birinde $(\% 6,6)$ nüks geliști. Bu oran daha önce bildirilenlerin altındadır ${ }^{11}$. Bizim düşüncemiz IGM tedavisinde, kontrendikasyon yoksa, geniş lokal eksizyon yapılmasıdır. Ayrıca yaygın tutulum veya apse oluşumu nedeniyle 9 hastada geniş lokal eksizyon yapılamadı. Bir hasta hariç, bütün hastaların lezyonları ortalama 5.1 ayda (aralık 3-10) düzeldi. Spontan düzelme ile ilgili olarak Lai ve ark. İGM li hastaların \%50'sinde ortalama 14.5 ayda tedavisiz spontan iyileşme rapor etmiştir ${ }^{16}$. Bileteral yaygın tutulumu olan bir olguda nüks ve apse oluşumu gözlendi. Apse oluşumu olan diğer hastalarda nüks gelişmedi.

Bazı yazarlar ${ }^{1}$ komplike ve dirençli veya yaygın lezyonlu vakalarda eksizyondan önce lezyonun küçültülmesini önermiştir, ancak istenmeyen etkilerin artma ihtimali vardır. Komplike vakalarımıza apse drenajı ve antibiyotik tedavisinden sonra steroid tedavisi önerdik, ancak bir hasta dışında diğerleri yan etki nedeniyle kabul etmedi. Hastalarımız konservatif tedavi ve takibi tercih ettiler. Bununla birlikte kortikosteroid tedavisinin zamanlaması süresi ve dozu ile ilgili konsensüs yoktur. Öte yandan bir kısım çalışmada kortikosteroid tedavisi ile 3 ile 10 ayda lezyon tam iyileşme gözlenmiştir ${ }^{19-25}$. Bizim çalışmamızda apse drenajı olan hastalarımızda ortalama 3.3 aylık sürede spontan düzelme oldu. Topikal steroid uygulamalarından fayda görüldügünü belirten çalışmalar ${ }^{25}$ olduğu gibi, kortikosteroid tedavisinin konservatif yaklaşımdan daha hızlı iyileştirip iyileștirmediğinin irdelenmesi gerekmektedir. Kanaatimiz spontan düzelme beklenenden erken olabilir. Kortikosteroid tedavisi başlanmadan önce, hastaya spontan düzelme şansı verilmesi gerektiği ve en az 3-6 ay beklenmesinin uygun olacağı kanaatindeyiz.

İGM'de geniş semptomatoloji, bulgular ve değişken seyirli olması nedeniyle uygun tedavi yaklaşımını seçip standardize etmek güçtür. Hangi tedavi yaklaşımı daha uygun olacaktır? $\mathrm{Ne}$ zaman geniş lokal eksizyon veya kortikosteroid tercih edilmelidir? Tüm hastalara aynı sürelerde aynı dozda kortikosteroid tedavisi uygulamak doğru mudur? Hasta kortikosteroidden çekindiğinde ne yapılmalıdır? Tüm bu sorular cevaplanmaya muhtaç durumdadır. İGM'ye yönelik standart tanı yöntemi ve tedavi yaklaşımının oluşturulması icin konservatif yaklaşım ile geniş lokal eksizyon ve/veya kortikosteroid 
uygulamasını karşılaştıran prospektif randomize çalışmalara ihtiyaç bulunmaktadır.

\section{SONUÇ}

İGM memenin nadir görülen benign bir enflamatuar hastalığıdır, ancak meme karsinomu ile karışabilir. Özellikle orta yaşlardaki kadınlarda, maligniteden ayırt edilemeyen veya basit mastit gibi düşünülen kitlelerin ayırıcl tanısında akılda bulundurulmalıdır. Spesifik bir görüntüleme bulgusu olmadığı için tanıda radyolojik yöntemler çok fazla yardımcı olamamaktadır. Kesin tanı için histopatolojik çalışma gerekir.

Halen İGM için genel kabul gören standart bir tedavi yaklaşım bulunmamaktadır. İGM'de klinik bulguları çok ciddi olmayan hastalarda başlangıç tedavisi olarak agresif cerrahi yaklaşımlardan kaçınmak gereklidir. Fakat medikal olarak hastalığın kontrol altına alınamadığı veya başlangıçtan itibaren ağır klinik bulgularla (tekrarlayan apse, fistül) seyreden hastalarda cerrahi kaçınılmaz olabilir. Mümkün olduğu durumlarda geniş lokal eksizyonun daha iyi sonuç verdiğini düşünmekteyiz. Öte yandan apse, fistül ve yaygin tutulumlu komplike vakalar tedaviyi ayrıca güçleştirmektedir. Çalışmamızda İGM’li hastalarda spontan düzelmenin olabildiği ve nüks oranının diğer çalışmalara benzer olduğu sonucuna ulaşılmıştır.

Çıkar Çatışması Beyanı: Yazarlar çıkar çatışması olmadığını bildirmişlerdir.

Finansal Destek: Bu çalışma her hangi bir fon tarafından desteklenmemiştir.

Declaration of Conflicting Interests: The authors declare that they have no conflict of interest.

Financial Disclosure: No financial support was received.

\section{KAYNAKLAR}

1. Al-Khaffaf B, Knox F, Bundred NJ. Idiopathic granulomatous mastitis: a 25-year experience. J Am Coll Surg. 2008;206:269-73.

2. Sakurai K, Fuhsaki S, Enomoto K, et al. Evaluation of follow-up strategies for corticosteroid therapy of idiopathic granulomatous mastitis. Surg Today. 2011;41:333-7.

3. Özel L, Ünal A, Ünal E, et al. Granulomatous mastitis: is it autoimmune disease? diagnostic and therapeutic dilemmas. Surg Today. 2012;42:729-33.

4. Akcan A, Akyildiz H, Deneme MA, et al. Granulomatous lobular mastitis:a complex diagnostic and therapeutic problem. World J Surg. 2006;30:1403-9.

5. Vinayagam R, Cox J, Webb L. Granulomatous mastitis: a spectrum of disease. Breast Care. 2009;4:251-4.

6. Gürleyik G, Aktekin A, Aker F, et al. Medical and surgical treatment of idiopathic granulomatous lobular mastitis: a benign inflammatory disease mimicking invasive carcinoma. J Breast Cancer. 2012;15:119-23.

7. Bakaris S, Yüksel M, Çiragil P, et al.Granulomatous mastitis including breast tuberculosis and idiopathic lobular granulomatous mastitis. Can J Surg. 2006;49:427-30.

8. Patel RA, Strickland P, Sankara IR, et al. Idiopathic granulomatous mastitis: case reports and review of literature. J Gen Intern Med. 2009;25:270-3.

9. Memis A, Bilgen I, Üstün EE, et al. Granulomatous mastitis: imaging findings with histopathologic correlaton. Clin Radiol. 2002;57:1001-6.

10. Azlina AF, Ariza A, Arni $\mathrm{T}$, et al. Chronic granulomatous mastitis: diagnostic and therapeutic consideration. World J Surg. 2003;27:515-8.

11. Gerber B, Heintze K, Stubert J, et al. Axillary lymph node disection in early-stage invasive breast cancer:is still standard today? Breast Cancer Res Treat. 2011;128:613-24.

12. Dursun M, Yilmaz S, Salmaslioglu A, et al. Multimodality imaging features of idiopathic granulomatous mastitis: outcome of 12 years of experience. Radiol Med. 2012;117:529-38.

13. Lacambra M, Thai TA, Lam CCF, et al. Granulomatous mastitis: the histological differentials. J Clin Pathol. 2011;64:405-11.

14. Tse GMK, Poon CSP, Law BKB, et al. Fine needle aspiration cytology of granulomatous mastitis. J Clin Pathol. 2003;56:519-21.

15. DeHertogh d, Rossof AH, Harris AA, et al. Prednisone management of graulomatous mastitis. N Eng J Med 1980;303:799-800.

16. Lal EC,Chan WC, Ma TK, et al. The role of cnservative treatment in idiopathic granulmatous mastitis. Breast J 2005;11:456-6.

17. Kim j,Tymms KE, Buckingham J. Methotrexate $n$ the management of granulomatous mastiti. ANZ J Surg 2003;73:247-9. 
18. Asoglu O, Ozmen V, Karanlık H, et al. Feasibility of surgical management in patients with granulomatous mastitis. Breast J 2005;11:108-14.

19. Kiyak G, Dumlu EG, Kilinc I, et al. Management of idiopathic granulomatous mastitis: dilemmas in diagnosis and treatment. BMC Surg. 2014;14:66-9.

20. Altıntoprak F, Baytekin HF, Altınay AE, ve ark. Meme kanserini taklit eden idiopatik granülomatöz mastit. Meme Sağlı̆̆ Dergisi 2009;5:40-3.

21. Hladik M, Schoeller T, Ensat F, et al. Idiopathic granulomatous mastitis: successful treatment by mastectomy and immediate breast reconstruction. J Plast Reconstr Aesthet Surg, 2011;64:1604-7.

22. Bouton ME, Jayaram L, O'Neill PJ, et al. Management of idiopathic granulomatous mastitis with observation. Am J Surg. 2015;210:258-62.
23. Pandey TS, Mackinnon JC, Bressler L, et al. Idiopathic Granulomatous Mastitis A Prospective Study of 49 Women and Treatment Outcomes with Steroid Therapy. The Breast Journal. 2014;20:258-266.

24. Sakurai K, Fujisaki S, Enomoto K, et al. Evaluation of follow-up strategies for corticosteroid therapy of idiopathic granulomatous mastitis. Surg Today. 2011;41:333-7.

25. Altıntoprak F, Kıvılcım T, Yalkin O, et al.Topical Steroids are effective in the treatment of Idiopathic Granulomatous Mastitis. World J Surg. 2015;39:271823. 